\title{
Ethnobiological Memoirs and Memory
}

\author{
OPENठACCESS \\ DOI 10.14237/ebl.7.2.2016.859
}

Copyright (c) 2016 by the author(s); licensee Society of Ethnobiology. This is an open-access article distributed under the terms of the Creative Commons Attribution-NonCommercial 4.0 International Public License (https://creativecommons.org/licenses/by-nc/4.0), which permits non-commercial use, distribution, and reproduction in any medium, provided the original author and source are credited.

The memoir, as an inherently personal narrative, is sometimes seen at odds with scholarly writing that demands an objective and detached approach. However, the building block of memoirs is the same as what leads to scientific progress: detailed observations. The difference perhaps lies in the goals and aims, as well as the scientist's preference for repeated observation versus unique or uncommon and thus anecdotal events. The personal insight becomes suspect and possibly unreliable for meaningful progress in the creation of knowledge. Such a position is untenable given the reality of science as both an inductive and deductive experience. Regardless, we have not carved out much space to allow for these sorts of reflections except perhaps at the end of a long and illustrious career. The scientific community has not always been kind to the memoir published too soon and thus supposedly tainted with an air of hubris.

The first recorded use of the word memoir in the English language, according to the Oxford English Dictionary (Simpson and Weiner 1989), appears in 1659 where it used to mean a record of events or history written from the personal knowledge or experience of the writer, or based on special sources of information. In short, a written memory. The process of memoir writing calls into question the nature of memory itself. The observer reflects and observes herself through the fog of past recollections. Yet, we all know the importance of taking good field notes with the expectation that some of what is observed may be useful later on with the benefit of hindsight and experience.

A few notable monographs have appeared over the last few decades that could be classified as ethnobiological memoir sensu lato. These books have taken many forms and approaches-from the hybrid memoir/historical hagiography (Davis 1996) to the swashbuckling adventure tale (Plotkin 1993) to the redemptive and spiritual (Nabhan 1993). Out of our larger community perhaps no one has reflected more consistently throughout his career as Nabhan, through numerous books as well as more recently a series of essays in the sister journal to this publication, Journal of Ethnobiology. Other ethnobiologists have used at least part of an otherwise data oriented and scientific monograph to reflect on the personal. We seem to be most at home when publishing memoirs in the long form and from the long view. Articles of the length more common to journals have been few and far between, either appearing in festschrifts or the occasional eureka moment emerging upon further reflection of field notes. A welcome change to this state of affairs comes from Justin Nolan and Andrea Pieroni (2013), who in recent years have started a series of memoir pieces derived from one's first time in the field in the Journal of Ethnobiology and Ethnomedicine.

This special issue of Ethnobiology Letters on Memoirs and Memory seeks to cherish the memoir, whenever written, and is based on a belief that the genre can make important contributions to the field of ethnobiology. Additionally, it suggests that relatively short pieces can yield significant insights. The advantage of a journal like Ethnobiology Letters is that encourages shorter pieces and articles, while still maintaining peer review standards and high editorial quality. What follows here is memoir in the broadest sense, both reflection and a return to the past in the form of unpublished data. We all too often plunge headlong into the future without time afforded to rethink and reevaluate previous fieldwork. We would do well to learn from those of our collaborators who reckon the geometry of time not in a linear sense but rather circular.

\section{References Cited \\ Davis, W. 1996. One River: Explorations and Discoveries in the Amaron Rain Forest. Simon \& Schuster, New York, NY.}


Nabhan, G.P. 1993. Songbirds, Truffles, and Wolves: An American Naturalist in Italy. Pantheon Books, New York, NY.

Nolan, J., and A. Pieroni. 2013. Recollections, Reflections, and Revelations: Ethnobiologists and Their "First Time" in the Field. Journal of Ethnobiology and Ethnomedicine 9:12. DOI: 10.1186/1746-4269-912.

December 29, 2016

John Richard Stepp

Department of Anthropology, University of Florida, Gainesville, FL, USA.

stepp@ufl.edu
Plotkin, M. J. 1993. Tales of a Shaman's Apprentice: An Ethnobotanist Searches for New Medicines in the Amazon Rain Forest. Viking, New York, NY.

Simpson, J. A., and E. S. C. Weiner. 1989. The Oxford English Dictionary. Clarendon Press, Oxford. 